\title{
An Exploratory Study of the Role of the Human Resource Information System Professional
}

\author{
By Sapora Bradley*
}

The increasing implementation of technology applications into the workplace has substantiated the need for adept professionals who can manage HR technology for employees and provide data about the organization. For some companies, these professionals are found within the human resources department. These information systems professionals combine HR knowledge and technology skills to provide applications that improve work processes and HR outcomes. This qualitative study focused on exploring the role delineation of human resource information systems (HRIS) professionals to better understand the advantageous aspects of the role's focus in HR technology and analytics. Specifically, the study aimed to describe how the HRIS professional role supports the functions of $H R$ and transformation of HR activities within organizations. Additionally, the research sought to uncover how HRIS professionals described their responsibilities and competencies in response to the significance of data analytics, as well as how the HRIS professionals described the outlook of their professional role. Ten, semi-structured interviews were conducted with HRIS professionals who reported having progressive HRIS experience within U.S. based organizations. The results included HRIS professionals' beliefs about their tasks, competencies, and job outlook and thematic analysis resulted in six categories: data management, HR/IT intersection, HRIS emergence, business intelligence, professional identity, and job satisfaction. The conclusions drawn from the research findings indicated that: HRIS professionals encourage HR technology integration to improve workplace processes; HRIS professionals manage data integrity and support the safeguarding of employee information; HRIS professionals run data inquiries and provide reports that influence decision making related to workforce and business outcomes; and HRIS professionals are enthusiastic about emergent job responsibilities in the design and coding of systems.

Keywords: Employee Data Management, Human Resource Information Systems, Human Resources, Role Delineation.

\section{Introduction}

With technology usage increasing and an influx of digital natives in the workforce, organizations are met with increasing demands to consider how to incorporate and manage technology applications for their employees (Bersin, 2016; Sierra-Cedar, 2016). In an increasingly competitive and complex business environment, HR technology has been promoted as a solution to simplifying work and cutting data complexity through improved systems (Weeks, 2013). As evolving technology and emerging best practices in workplace processes continue to transform organizations, HRIS professionals hold a unique positioning at the intersection of understanding HR functions and technology solutions. A survey of 32,000 HR professionals, leading to the report on Human Resources Competency

${ }^{*}$ Researcher, Pepperdine University, USA. 
(SHRM, 2012), found that although being a proponent of technology was considered a desirable trait, the perceived impact on HR effectiveness and the perceived impact of technology on business performance were low. Additionally, the report on Global Human Capital Trends revealed little urgency among respondents concerning the adoption of HR technology (Deloitte Consulting, 2014). The intersection between IT and HR can pose problems when IT is not invested as stakeholders in HR software solutions. To earn support from executives and other functional areas, a demonstrated need must occur concerning the role of HRIS and its importance. When HR is unable to defend a technological business strategy with metrics and analytics investment is denied and allocated to other departments within the organizational (Higgins, 2014).

A crucial assumption about this study is the need to have HR technology managed by the HR function rather than the IT function. This stance is based on the researcher's own experience at organizations without dedicated HRIS staff, where technology solutions were heavily influenced by IT workload and stake in new projects. It is therefore assumed that technology is at the intersection of IT and HR, signaling that a difference exists concerning the perceived importance of human capital management (HCM). This study also assumes that HRIS is a necessary component for all organizations regardless of size and industry. It was the researcher's intent to utilize the research data to uncover professional opinions about how the participants are applying HRIS principles within various organizational landscapes.

To understand the trajectory of the HRIS professional and establishment within organizations this study posed a central guiding question and two subquestions:

- How does the HRIS professional role support the functions of HR and transformation of HR activities within organizations?

- How do HRIS professionals describe the responsibilities and competencies of the role in response to the emergence of big data?

- How do HRIS professionals describe the outlook of their professional role within organizations and the HR profession?

To examine the HRIS professional role, two concepts were considered when analyzing the research data. Organizational role theory and delineation describes how employees define their role and how other professionals respond to such definitions (Naikar, 2013; Prien, 2009). Additionally, the study considered HCM theory and the contribution of HRIS professionals to an organization's competitive advantage. The HCM theory also assesses how HR technology influences the management of the HR functions (Sierra-Cedar, 2014).

\section{Literature Review}

The topic of HRIS solutions is most often found within e-human resource management (HRM) literature, where these systems are considered a tool for HR 
departments. Martinsons (1997) had defined HRIS as consisting of sophisticated information technology tools which improve HR processes and contributes to the quality of human capital within organizations. Hendrickson (2003) expands and identifies HRIS as more than the use of software but a system inclusive of technology, end-users, data, and policies. Bondarouk et al. (2009) described an HRIS as providing multiple services covering three main functions: operations of daily transactions, relational communication between stakeholders, and transformational decision making.

Mayfield et al. (2003) stipulate that the goal of an HRIS is to harness technology as a tool which can lower barriers to HR's strategic efforts. Different activities, such as solutions for recruiting, payroll, and self-service are therefore undertaken with a new emphasis on technology as many of these transactional activities have been characterized as ideal for automation (Bersin, 2017). By automating the operational, HR departments leverage technology in order to free up resources to do other, more strategic work.

Lepak and Snell (1998) characterized HRIS software as being a relational database for stakeholders, where information is collected and then shared between other functional departments within the organization. Firestone and McElroy (2003) explained that this intra-organizational communication of data represents double-loop learning and feedback as individuals continuously draw conclusions from beliefs, actions, and reactions that are occurring within the organization. While Casalino et al. (2015) described the success of systems implementations as being influenced by paths to organizational learning.

Research reveals a chasm between the potential proposed by HRIS adoption and the actual success of enterprise-wide HRIS (Tansley and Watson, 2000). In addition to challenges related to investment and resource allocation, criticism about HRIS may contribute to difficulty in solution integration. These criticisms include the belief that operational efficiencies should be attributed to IT departments and not to HR departments, as well as a belief that HR departments benefit from automation service, while other departments within an organization see little direct value (Martinsons, 1997; Panayotopoulou et al., 2010; Strohmeier, 2007). However, it is ideal for HR, IT, and business departments to work together when evaluating and appraising existing HCM procedures and the integration of HRIS solutions.

Concerning technology adoption among employees, literature addresses an organization's need to innovate or perish. Organizational behavior theories indicate strong responses to external threat factors within the business landscape that results from vendor promotion, government policies, and competitive pressure within the industry (Silverstein et al., 2012). Cummings and Worley (2015) attributed the response to transformation and rate of change as being dependent upon both internal and external factors that are imposed on the organization. Guzmán-Cuevas, Cáceres-Carrasco, and Soriano (2009) attributed innovation to a dependency on current economic conditions. Brynjolfsson and McAfee (2014) address an organization's IT investment as a leading factor for business management innovation. 
Factors for implementing technology innovation will be specific to the individual organization. The technology acceptance model indicates that the perceptions of usefulness and ease of use are the determinants of technology adoption among organizational employees (Davis, 1989). Similarly, perceived effort and time to learn new technologies affected adoption among employees (Goodman and Darr, 1998). Kim and Lee (2006) also supported the ease of use factor and suggested the importance of a culture of acceptance. Overall, the value of an HR technology product will be determined by the practitioners and endusers. The gap in technology adoption is also influenced by the perceived costs of implementation (Moore, 1999; Smolcic et al., 2014).

Bell et al. (2006) discussed the influence IT departments have concerning HR's technology transformation. However, literature is lacking in research related to the adoption of specific HRIS infrastructure. There are publications about how a new system becomes implemented within a particular organization, but there is little guidance about who should lead, maintain, and be a part of the drive for future HR innovations to keep up with continuously evolving technologies.

A review of HRIS job postings retrieved from LinkedIn and SHRM revealed several key characteristics related to technical complexity, innovation, and autonomy. Concerning the administrative function, HRIS professionals are in charge of collecting data and maintaining it in standardized formats. With respect to project management, HRIS professionals are tasked with preparing upgrades and enhancements to HRM systems, leading user testing, and making recommendations for technology policies. Responsibilities surrounding analytics encompass evaluating workflows for improvement opportunities, running queries and reports for the business function, and utilizing mathematical models to interpret raw data and make predictions about human capital needs (Dussert, 2014). A survey by the Information Services Group sought to identify goals of HRIS managers in various organizations. Objectives included speedy implementation of new systems, improved user experience with technology, and identification of data shortfalls in the current organizational design (Sivak and Card, 2014).

\section{Methodology}

Based on the limited foundational research about HRIS professionals, this study utilized an exploratory approach to inquiry. Stebbins (2001) defines exploratory research as an effort to more thoroughly explain an idea or observation from the standpoint of the target population's attitudes, opinions, and behavior associated with the topic. This type of research is conducted before engaging in qualifying research that generalizes findings. This exploratory study utilized the qualitative research technique of interviewing. Recruitment and purposive sampling stipulated that participants have seven years of progressive work experience dedicated to the HRIS specialty, work at a U.S. based enterprise, and preferably hold a higher education degree in HR or IT. Organization size and industry were expected to be varied as participants were anticipated to share their 
experiences within HRIS before their current job role, thus having occurred across numerous organizations. The researcher believed that experienced professionals could speak to fluctuating workforce trends and demands for technology in the workplace. Ten HRIS professionals participated in interviews with the researcher. Although this study did not seek a statistically representative sample, the use of experts contributed to the credibility of the study results. According to Gobet's (2016) definition, an expert is an individual having knowledge and experience of the topic being discussed.

Prior to beginning the interview, the researcher and interviewee discussed the IRB approved informed consent form and the researcher answered any questions that the interviewee had about the study or interview process, including confidentially concerns. Interviews were conducted by phone or FaceTime and lasted between 45-55 minutes. The logistics and feasibility of the study were tested with a pilot study conducted with two HRIS professionals who met the criteria of the sample population.

The researcher followed a semi-structured interview protocol and inquired about their educational backgrounds, employment history, and professional development. The participants also responded to questions about their entry into the specialty, their job responsibilities, and their opinions about HRIS in the workplace. To confirm the internal validity of the interview approach, interview questions posed by the researcher were first examined by a professional familiar with HRIS topics and interview protocol.

The interviews were audio recorded and then transcribed using HyperTRANSCRIBE, an audio transcription tool. The researcher also took detailed handwritten notes and memos to capture other specifics that occur during the interview such as making notations about tone, body language, or implications that are not easily gleaned from the audio recordings alone. Kvale and Brinkman (2009) noted that other information in addition to the words spoken can be found within the interview. It is the researcher's task to determine the full message being expressed by the participant and to capture those impressions within the moment.

A system was developed by the researcher to code interview responses. These codes were used to determine patterns in the data, identify themes, and comprehend the overarching connections across categories (Charmaz and Belgrave, 2012; Creswell, 2013). Each interview then received an in-depth review by the researcher. This focused reading familiarized the researcher with the data in an attempt at identifying all possible coding opportunities. The researcher also used qualitative research software, HyperRESEARCH, to organize data and codes from the interviews. After the basic coding, more interpretive coding occurred to engage in thematic and narrative analysis related to the participant's opinions, personal experiences, and perceptions. The researcher conferred with a peer reviewer who evaluated the researcher's coding scheme and examined the consistency of the coding. The researcher and peer reviewer also discussed appropriate changes to the codebook. 
Vol. 6, No. 1 Bradley: An Exploratory Study of the Role of the Human Resource...

\section{Results}

Table 1 lists the participants by code and includes number of years within the HRIS specialty and current business industry.

Table 1. Interviewee Demographics

\begin{tabular}{|l|c|c|}
\hline Participant Code & Time as HRIS Professional & Current Industry \\
\hline $3 Z 2$ & 14 years & Technology \\
\hline 6MF & 5 years & Education \\
\hline 7N7 & 20 years & Education \\
\hline CTG & 18 years & Healthcare \\
\hline EH8 & 7 years & Education \\
\hline PC9 & 8 years & Healthcare \\
\hline T3U & 9 years & Energy \\
\hline V68 & 38 years & Education \\
\hline XGE & 10 years & Consulting \\
\hline ZWU & 7 years & Education \\
\hline
\end{tabular}

The exploratory nature of the design provided an extensive amount of data. The qualitative analysis of the interviews resulted in 724 coded passages grouped into six categories (a) data management, (b) HR/IT intersection, (c) HRIS emergence, (d) business intelligence, (e) professional identity, and (f) job satisfaction. Table 2 lists the six categories with themes and counts. Additional sub-themes were identified and aided the researcher during data analysis.

Table 2. Thematic Categories

\begin{tabular}{|l|c|c|}
\hline Category & Theme & Count \\
\hline Data Management & Curation & 51 \\
\hline & Ownership & 19 \\
\hline HR/IT Intersection & Resources & 72 \\
\hline & Structure & 45 \\
\hline HRIS Emergence & Task Allocation & 26 \\
\hline & Culture & 26 \\
\hline Business Intelligence & Career Outlook & 23 \\
\hline & Technology & 55 \\
\hline & Data Leverage & 13 \\
\hline Professional Identity & Insights & 28 \\
\hline & Reporting & 30 \\
\hline & Education & 15 \\
\hline & Job Role & 81 \\
\hline & Motivations & 37 \\
\hline Job Satisfaction & Perceptions & 88 \\
\hline No: $N=$ Previous Experience & 41 \\
\hline & Professional Development & 48 \\
\hline
\end{tabular}

Note: $N=724$ coded passages. 


\section{Discussion of Key Findings}

Participants spoke to the emergence of HRIS in response to industry norms and organizational culture. Many associated the growth of HRIS with the usage of technology by employees and the collection of employee data. In general, participants stated that HRIS emergence was a direct response to technology trends. The data implied that there was a generational difference, where younger employees were more adapt with technology, but would become frustrated with certain limitations. Other generations appeared to place more responsibility on the HRIS professionals and had a more difficult time adapting to new work processes.

Participants described data management concerns, including data integrity, compliance, and moving away from paper collection methods toward more simplified digital capturing. Attention was given to the ownership of data as related to how information was stored, made available, and disseminated to the appropriate parties. A concern about storing data in-house versus the cloud presented itself among participants who suggested that it was useful for certain sized organizations, but at the cost of losing some amount of control over the data. Participants also described application and enterprise development, customization, and the cost-benefit comparison to homegrown resources.

HRIS professionals discussed their organization and departmental structures, including sizes of organizations they had worked at and how implementation projects were staffed. In some cases, the HRIS professional was classified under the IT department. There were also instances where organizations did not have an IT resource in-house. Participants considered task allocation between HRIS and IT professionals and classified tasks that were distinct to each role.

Participants described executive interest in data leverage and provided examples of desired employee outcomes. Participants spoke considerably about report pulling, including creating their own custom reports, using reports from vendor applications, and combining reports. Most participants believed that their organizations embraced metrics but indicated that their organizations fell short of utilizing data reports to produce predictive outcomes. The consensus seemed to be that organizations were not actively developing analytic models.

\section{Conclusions and Implications}

The first conclusion states that HRIS professionals encourage HR technology integration to improve workplace processes by disrupting outdated and inefficient manual processes within the workplace. The HRIS professionals interviewed are knowledgeable about processes, organizational data, and technology trends. Participants described their efforts in researching and vetting HRIS applications and systems for implementation into their organizations. Much of their time was dedicated to meeting with end users and seeking the best solutions to improve their day-to-day activities. This conclusion considers HRIS professionals as HR technology experts, seeking a balance between knowledge and application (Stokes, 1997). HRIS professionals benefit from actively engaging in the specialty 
by seeking professional certifications, attending conferences, and communicating with their personal learning networks to expand their knowledge. This finding supports Bailey (2015) whose phenomenological study revealed that professional development is part of the HR practice and that non-formal learning is experienced as a means of professional development. The study participants demonstrated that successful HRIS professionals are problem-solvers and systematic and analytical thinkers.

The second conclusion states that HRIS professionals manage data integrity and the gatekeeping of employee information. HRIS helps organizations with complex employee classifications, and therefore complex data. Participants described the influx of employee data and the need to confirm correct information about employees, comply with retention laws, and oversee the access and dissemination of employee information and workforce data shared within the organization. This finding considers role theory, as several of the professionals interviewed described that the crossover of HRIS and IT raised questions about the boundaries related to where responsibility lies with HRIS applications and systems, and employee data. As noted by Stamper and Johlke (2003) organizations consider role theory by addressing role conflict and role ambiguity. Additionally, some participants attested to collaborative efforts with other departments as being positive experiences, whereas others had experienced instances where there was lack of engagement. Therefore, conflicts can be lessened by engaging in reoccurring meetings, collaborative projects, and embracing opportunities for knowledge transfer. These findings support the work of Cerra et al. (2013) who concluded that collaboration was a means of navigating organizational politics. Collaborative engagement can, therefore, improve the relationship between HR and IT departments concerning systems implementations.

The third conclusion states that HRIS professionals run data inquiries and provide reports that influence decision making related to workforce and business outcomes. Participants revealed that pulling reports and data mining was a significant feature of their role. Participants described the various requests for metrics concerning employee data and human capital figures that were requested by executives and other leaders. HRIS professionals were adept at making customized reports by combining several reports into one. This was essential when the participants concluded that a customized report would contribute to a better narrative for the requestor. Literature indicates that knowledge of metrics and analytics lead to actionable insights and therefore improved business outcomes (Weisbeck, 2016). SHRM (2012) identified technology usage as a means to solve business problems as a competency related to business acumen. For HR departments, the reporting of metrics and further consideration of analytics becomes an essential component that moves the HR function from operational to strategic tasks. As suggested by the HCM theory, HR then becomes an asset by improving business outcomes and talent appraisal (National Academies of Sciences, Engineering, and Medicine, 2017; Sierra-Cedar, 2014). Therefore, HRIS' reporting responsibilities support outcomes of various HR functions, such as recruiting, training, compensation and benefits, and succession planning. 
However, the HRIS professionals agreed that big data analytics to make predictions was emerging but consequently underutilized in the workplace.

The fourth conclusion states that HRIS professionals are enthusiastic about emergent job responsibilities in HRIS system design and coding. Participants described basic coding that they utilize during system implementations and upgrades. Respondents enjoyed the challenging nature of combining HR knowledge and people skills with technology solutions. HRIS professionals discussed workarounds and customizations that they aimed to complete for end users. Additionally, HRIS professionals expressed interest in gaining more education in IT specific areas and some had already sought system certifications from product vendors that they are currently using in-house. Several HRIS professionals insisted that they identified as technology professionals and as having a knack for technology. There were also opportunities for HRIS professionals to make lateral movements into IT. These results also concern role theory as it relates to professional identify and self-identification of the participants as being tech savvy (Walsh and Gordon, 2008). These findings support the work of Lawler and Boudreau (2015) whose yearly surveys indicated increased satisfaction among HR professionals with utilizing technical skills. Therefore, these new skills also contribute to contentment and satisfaction among HRIS professionals.

Practice and research related recommendations emerged from the data. Interview participants described resistant attitudes from end users, suggesting that HRIS professionals needed to gain stakeholder confidence. Mondare et al. (2011) discussed the importance of executive buy-in. As mentioned by the participants, individuals in leadership positions typically recognized the value of HRIS. Therefore, leaders and executives can influence the opinions of end users as to the helpfulness and credibility of HRIS professionals by expressing buy-in, in a way that is visible and impactful on the culture of the organization. This could potentially encourage better working relationships between HRIS professionals and end users.

Given that some participants described their organizations as not using HR analytics, it is recommended that companies lacking in data analytics consider developing an organizational analytics team that makes use of data within the organization and develops analytic models. Roles on this team would include a project manager, business analyst, and database administrator (EMC Education Services, 2015). In this capacity, HRIS professionals would play a significant role in developing measures for big data analytics. HRIS professionals would be unique contributors to an analytics team, because they are very familiar with people data and can represent the interests of the HR department.

The interviews also revealed opportunities for additional research. With participants discussing the cost savings associated with the adoption of cloudbased systems and the outsourcing of the IT function, it is recommended that research is conducted concerning this trend. Specifically, how this trend might reveal information about the development of new HRIS skills in coding and system management in organizations. Research can be specific to industry and organization size in demonstrating the consolidation of responsibilities. 
The sample focused on HRIS professionals with seven years of progressive HRIS experience in U.S. based organizations. The recruitment parameters did not reflect the youngest generation in the workforce. As the workforce is nearing a changing tide concerning preparation and technology fluency, there probably are insights into the proclivity for technology and the self-identification of the upcoming HRIS leaders and their end users that these professionals' views did not address.

\section{Closing Remarks}

This study involved HRIS professionals of various titles and from various industries. This produced extensive amounts of data, which was helpful in the board, exploratory sense however industry specific or role specific conclusions cannot be made. Researcher bias was considered, as the researcher was interested in this topic because of previous work experience in both the HR and IT departments. To convey accurate interpretation to the reader, the researcher engaged in reflexivity throughout the study including validation and pilot testing of the interview questions. Multiple reviews and coding of interview transcripts occurred, and a peer reviewer was recruited to ensure consistency of the interpretation of the interview data.

The study provided an in-depth analysis of the preparation and responsibilities of HRIS professionals and comments on the outlook for the profession. The results of this study confirmed that HRIS professionals help improve work processes by procuring useful applications for employees. Additionally, HRIS professionals can contribute to HR's strategic positioning within organizations by reporting actionable insights and thus encouraging the movement toward predictive analytics.

\section{References}

Bailey, M. (2015). Professional development of HR practitioners: A phenomenographic study. European Journal of Training and Development, 39(3), 220-238. Doi: 10.11 08/EJTD-08-2014-0057.

Bell, B., Lee, S., Yeung, S. (2006). The impact of e-HR on professional competence in HRM: Implications for the development of HR professionals. Human Resource Management, 45(3), 295-308. Doi: 10.1002/hrm.20113.

Bersin, J. (2016). Predictions for 2017: Everything is becoming digital. Retrieved from https://www2.deloitte.com/content/dam/Deloitte/at/Documents/about-deloitte/predi ctions-for-2017-final.pdf.

Bersin, J. (2017). Transformative Tech: A disruptive year ahead. HR Magazine, 62(1),

28-36. Retrieved from https://www.shrm.org/hr-today/news/hr-magazine.

Bondarouk, T., Ruël, H. and van der Heijden, H. (2009). e-HRM effectiveness in a public sector organization: A multi-stakeholder perspective. The International Journal of Human Resource Management, 20(3), 578-590. Doi: 10.1080/09585190802707359.

Brynjolfsson, E. and McAfee, A. (2014). The second machine age: Work, progress, and prosperity in a time of brilliant technologies. New York, NY: Norton \& Company. 
Casalino, N., Cavallari, M., DeMarco, M., Ferrara, M., Gatti, M. and Rossignoli, C. (2015). Performance management and innovative human resource training through flexible production systems aimed at enhancing the competitiveness of SMEs. The IUP Journal of Knowledge Management, 13(4), 29-42. Retrieved from http://www. iupindia.in/Knowledge_Management.asp.

Cerra, A., Easterwood, K. and Power, J. (2013). Transforming business: Big data, mobility, and globalization. Indianapolis, IN: Wiley.

Charmaz, K. and Belgrave, L.L. (2012). Qualitative interviewing and grounded theory analysis. In J. F. Gubrium, J. A. Holstein, A. B. Marvasti and K. D. McKinney (Eds.), The SAGE handbook of interview research: The complexity of the craft (pp. 347366). Thousand Oaks, CA: SAGE Publications.

Creswell, J. W. (2013). Qualitative inquiry and research design: Choosing among five approaches. Los Angeles, CA: SAGE Publications, Inc.

Cummings, T. G. and Worley, C. G. (2015). Organization development \& change. Stamford, CT: Cengage Learning.

Davis, F. D. (1989). Perceived usefulness, perceived ease of use, and user acceptance of information technology. MIS Quarterly, 13(3), 319-340. Retrieved from http://www. misq.org.

Deloitte Consulting. (2014). Global human capital trends 2014: Engaging the 21-century workforce. Retrieved from https://bit.ly/2o2GhQO.

Dussert, B. (2014). HR should hire 'scary' data people. Forbes. Retrieved from http://www. forbes.com.

EMC Education Services. (2015). Data science and big data analytics: Discovering, analyzing, visualizing and presenting data. Indianapolis, IN: Wiley.

Firestone, J. M. and McElroy, M. W. (2003). Key issues in the new knowledge management. Boston, MA: Butterworth-Heinemann.

Gobet, F. (2016). Understanding expertise: A multi-disciplinary approach. London, UK: Palgrave Macmillan.

Goodman, P. S. and Darr, E. D. (1998). Computer-aided systems and communities: Mechanisms for organizational learning in distributed environments. MIS Quarterly, 22(4), 417-440. Retrieved from http://www.misq.org.

Guzmán-Cuevas, J., Cáceres-Carrasco, R., \& Soriano, D. (2009). Functional dependence and productive dependence of SMEs. Small Business Economics, 32(3), 317-330. Doi: 10.1007/s11187-008-9115-0.

Hendrickson, A. R. (2003). Human resource information systems: Backbone technology of contemporary human resources. Journal of Labor Research, 24(3), 381-394. Retrieved from https://link.springer.com/journal/12122.

Higgins, J. (2014, November). Bringing HR and finance together with analytics. $H R$ Magazine, 59(11), 44-46. Retrieved from https://www.shrm.org/hr-today/news/hrmagazine.

Kim, S. and Lee, H. (2006). The impact of organizational context and information technology on employee knowledge-sharing capabilities. Public Administration Review, 66(3), 370-385. Doi: 10.1111/j.1540-6210.2006.00595.x.

Kvale, S. and Brinkman, S. (2009). Interviews: Learning the craft of qualitative research interviewing $\left(2^{\text {nd }}\right.$ ed.). Thousand Oaks, CA: Sage Publications.

Lawler, III, E. E. and Boudreau, J. W. (2015). Global trends in human resource management: A twenty-year analysis. Stanford, CA: Stanford University Press.

Lepak, D. P. and Snell, S. A. (1998). Virtual HR: Strategic human resource management in the $21^{\text {st }}$ century. Human Resource Management Review, 8(3), 215-234. Retrieved from https://www.journals.elsevier.com/Human-Resource-Management-Review. 
Martinsons, M. G. (1997). Human resource management applications of knowledge-based systems. International Journal of Information Management, 17(1), 35-53. doi: 10.1016/S0268-4012(96)00041-2.

Mayfield, M., Mayfield, J. and Lunce, S. (2003). Human resource information systems: A review and model development. Advances in Competitiveness Research, 11(1), 139152. Retrieved from https://bit.ly/2zutq19.

Mondare, S., Douthitt, S. and Carson, M. (2011). Maximizing the impact and effectiveness of HR analytics to drive business outcomes. People \& Strategy, 34(2), 20-27. Retrieved from http://www.hrps.org/?page=PeopleStrategy.

Moore, G. A. (1999). Crossing the chasm: Marketing and selling high-tech products to mainstream customers. New York, NY: Harper Business.

Naikar, N. (2013). Work domain analysis: Concepts, guidelines, and cases. Boca Raton, FL: CRC Press.

National Academies of Sciences, Engineering, and Medicine. (2017). Information technology and the U.S. workforce: Where are we and where do we go from here? Doi:10.17226/24649.

Panayotopoulou, L., Galanaki, E. and Papalexandris, N. (2010). Adoption of electronic systems in HRM: Is national background of the firm relevant? New Technology, Work and Employment, 25(3), 253-269. Doi: 10.1111/j.1468-005X.2010.00252.

Prien, E. P. (2009). A practical guide to job analysis. San Francisco, CA: Pfeiffer.

SHRM. (2012). Content validation study of the SHRM competency model. Retrieved from https://bit.ly/2zxWlRN.

Sierra-Cedar. (2014). HR systems survey white paper, $17^{\text {th }}$ annual edition. [White paper]. Retrieved from https://www.sierra-cedar.com/research/publications.

Sierra-Cedar. (2016). HR systems survey white paper, $19^{\text {th }}$ annual edition. [White paper]. Retrieved from https://www.sierra-cedar.com/research/publications.

Silverstein, D., Samuel, P. and DeCarlo, N. (2012). The innovator's toolkit: 50+ techniques for predictable and sustainable organic growth. Hoboken, N.J: John Wiley \& Sons.

Sivak, M. and Card, D. (2014). Human resources technology and service delivery trends in 2014. [Executive Summary]. Retrieved from http://info.isg-one.com/2014-HR-Tec hnology-and-Service-Delivery.html.

Smolcic, N., Thomas, B. and Contacos-Sawyer, J. (2014). The advantages and affordability of human resource information system's (HRIS) implementation in the small business sector. Competition Forum, 12(2), 8-15. Retrieved from http://www. eberly.iup.edu/ASCWeb/journals_cf.html.

Stamper, C. L. and Johlke, M. C. (2003). The impact of perceived organizational support on the relationship between boundary spanner role stress and work outcomes. Journal of Management, 29(4), 569-588. Doi: 10.1016/S0149-2063(03)00025-4.

Stebbins, R. A. (2001). Exploratory research in the social sciences. Thousand Oaks, CA: SAGE Publications.

Stokes, D. E. (1997). Pasteur's quadrant: Basic science and technological innovation. Washington, DC: The Brookings Institution.

Strohmeier, S. (2007). Research in e-HRM: Review and implications. Human Resource Management Review, 17(1), 19-37. Doi: 10.1016/j.hrmr.2006.11.002.

Tansley, C. and Watson, T. (2000). Strategic exchange in the development of human resource information systems (HRIS). New Technology, Work \& Employment, 15(2), 108-122. Retrieved from https://bit.ly/1V0fuD0.

Walsh, K. and Gordon, J. R. (2008). Creating an individual work identity. Human Resource Management Review, 18(1), 46-61. Doi: 10.1016/j.hrmr.2007.09.001. 
Weeks, K. O. (2013). An analysis of human resource information systems impact on employees. Journal of Management Policy \& Practice, 14(3), 35-49 Retrieved from http://www.na-businesspress.com/JMPP/WeeksKO_Web14_3_.pdf.

Weisbeck, D. (2016). Why connecting workforce outcomes to business outcomes matters. Retrieved from https://bit.ly/2Q1Aq7v. 
